\title{
Thoughts on the discussion about the revision of the International Classification of Functioning, Disability and Health (ICF) scheme
}

\section{Considerações sobre a discussão da revisão do esquema da Classificação Internacional de Funcionalidade, Incapacidade $e$ Saúde (CIF)}

(DShamyr Sulyvan de Castro1, (D) Paulo Sergio Batista de Almeida Filho², (1) Mara Franklin Bonates², (D) Maria Caroline Silva ${ }^{1}$, (Duciana Castaneda Ribeiro ${ }^{3}$

1Physical Therapy Departament, Universidade Federal do Ceará - UFC

${ }^{2}$ Virtual University Institute, Universidade Federal do Ceará - UFC

${ }^{3}$ Instituto Federal do Rio de Janeiro - IFR

\section{Mailing address:}

Shamyr Sulyvan Castro

E-mail: shamyrsulyvan@gmail.com

Submitted: May 18, 2020

Accepted: June 02, 2020

\section{How to cite}

Castro SS, Almeida Filho PSB, Bonates MF, Silva MC, Ribeiro LC. Thoughts on the discussion about the revision of the International Classification of Functioning, Disability and Health (ICF) scheme. 2019;26(4):230-233

DOI: 10.11606/issn.2317-0190.v26i4a169816

\begin{abstract}
The International Classification of Functioning, Disability and Health (ICF) presents an innovative approach to functioning: the biopsychosocial model. Since then, the ICF framework and its explanatory scheme has been used in many settings, including health, social security, and education. Recently, some criticism has arisen and proposals have ensued regarding its revisions. Objective: This paper discusses previous proposals for revisions to the ICF scheme and present suggestions of a new one. Methods: We outline some of the suggestions of ICF alternative functioning schemes, and present some of their features. Results: We also propose our own scheme, highlighting its advantages over predecessors. In our proposal, current scheme components are kept and arranged equidistantly along a three dimension 'ball shell' structure connected by double-headed arrows. Our scheme is innovative in that it does not present any component as central, allowing the scheme to be more adaptable to the reality of each functioning profile. It is also dynamic, by rotating on 3 axes, making possible the central positioning of the most important component. The spheres for each component can be enlarged, demonstrating the magnitude of each component. Conclusion: We hope to contribute to the current discussion on ICF scheme and its revision.
\end{abstract}

Keywords: International Classification of Functioning, Disability and Health, Disability Studies, Models, Theoretical

\section{RESUMO}

A Classificação Internacional de Funcionalidade, Incapacidade e Saúde (CIF) apresenta uma abordagem inovadora ao funcionamento: o modelo biopsicossocial. Desde então, a estrutura da CIF e seu esquema explicativo têm sido utilizados em muitos contextos, incluindo saúde, previdência social e educação. Recentemente, surgiram algumas críticas e surgiram propostas a respeito de suas revisões. Objetivos: Este artigo discute propostas anteriores de revisões do esquema da CIF e apresenta sugestões de uma nova. Métodos: Descrevemos algumas das sugestões de esquemas de funcionamento alternativo da CIF e apresentamos algumas de suas características. Resultados: Também propomos nosso próprio esquema, destacando suas vantagens sobre os antecessores. Em nossa proposta, os componentes atuais do esquema são mantidos e dispostos equidistantemente ao longo de uma estrutura tridimensional de "casco de bola" conectada por setas de duas pontas. Nosso esquema é inovador, pois não apresenta nenhum componente como central, permitindo que o esquema seja mais adaptável à realidade de cada perfil funcional. Também é dinâmico, girando em 3 eixos, possibilitando o posicionamento central do componente mais importante. As esferas para cada componente podem ser ampliadas, demonstrando a magnitude de cada componente. Conclusão: Esperamos contribuir para a discussão atual sobre o esquema da CIF e sua revisão.

Palavras-chave: Classificação Internacional de Funcionalidade, Incapacidade e Saúde, Estudos sobre Deficiências, Modelos Teóricos 


\section{INTRODUCTION}

In 2001, the World Health Organization, published the International Classification of Functioning, Disability and Health (ICF). The ICF concept of health and disability is based on a multidimensional and universal approach to disability, which is placed on a continuum with health. Thus, functioning should be conceived as a continuum of health states, with people experiencing various degrees of functioning. ${ }^{1}$ From the ICF perspective, disability is not merely a problem that arises from a person's body, but also a contextdependent health experience.

According to the ICF, disability and functioning are the result of interactions between health conditions (diseases, disorders, and injuries) and contextual factors. Moreover, ICF advocates that functioning and disability are universal experiences, applicable to all people and that disability is not the mark of a restricted social group. In other words, disability is a universal feature of the human condition over one's lifespan. ${ }^{1}$

This is possible because ICF presents a model of functioning based on the biopsychosocial approach, considering as its elements 'Health Condition', 'Body Functions and Structures', 'Activities', 'Participation', and 'Environmental and Personal Factors. ${ }^{2}$ The adoption of this approach of functioning represented an interruption in the hegemony of the biomedical model, which had been in force until then. ${ }^{3}$ Since its publication, many articles discussing the educational, clinical, statistical, and theoretical purposes of ICF have been published. ${ }^{4}$

Amid the accumulation of such research, criticism of ICF scheme has occurred among users and researchers. In this context, this paper presents some proposals to revise the ICF scheme and provide suggestions for a new visual scheme.

\section{Scientific debate surrounding the ICF scheme update}

A discussion on the need to update ICF scheme was started in 2017 when the first alternative paper was published, ${ }^{5}$ followed by four other publications discussing and presenting new schemes. ${ }^{6-9}$ The first paper published introduced three alternative ICF schemes. In the first paper, there is only one difference, which is that there is no "health conditions" listed in the domains [Figure 1]. The rest of the scheme is the same as in the original ICF scheme.

The second alternative ICF scheme presents Functioning and Disability as a combination of personal factors and Participation, Activities, and Functions/Structures. Participation, Activities, and Functions/Structures are connected by double-headed arrows; Functioning is also linked by a double-headed arrow to Personal Factors (including [co]morbidity).

This system (Personal Factors + Functioning) is placed in and limited by Environmental Factors [Figure 2 ]. The third scheme is a variation of the second, in which Participation gains a central position [Figure 3]. ${ }^{5}$

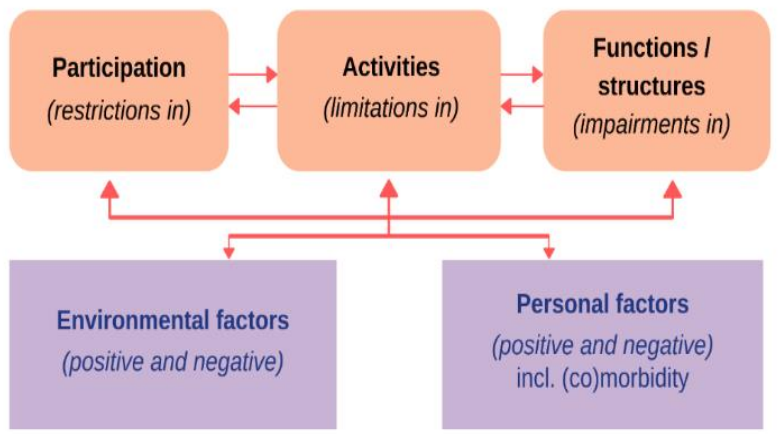

Figure 1. First model suggestion - without health conditions ${ }^{5}$

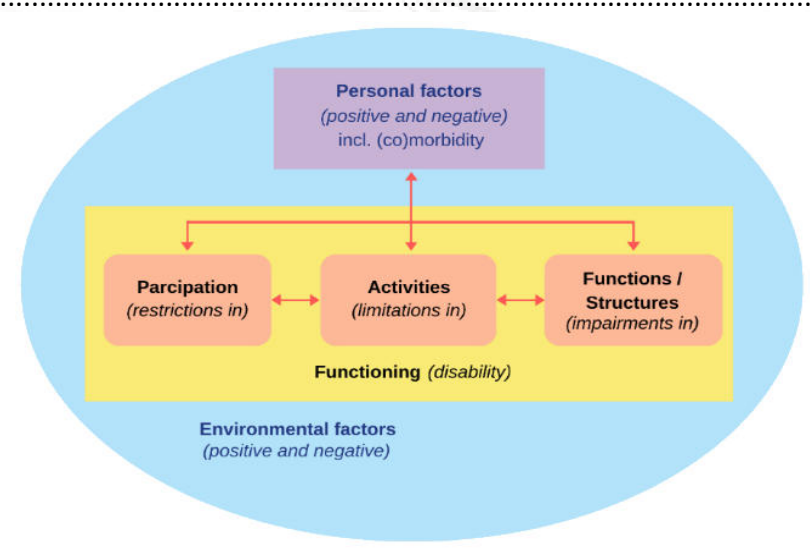

Figure 2. Second suggestion model - Functioning and Disability as a combination of Participation, Activities, and Functions/Structures ${ }^{5}$

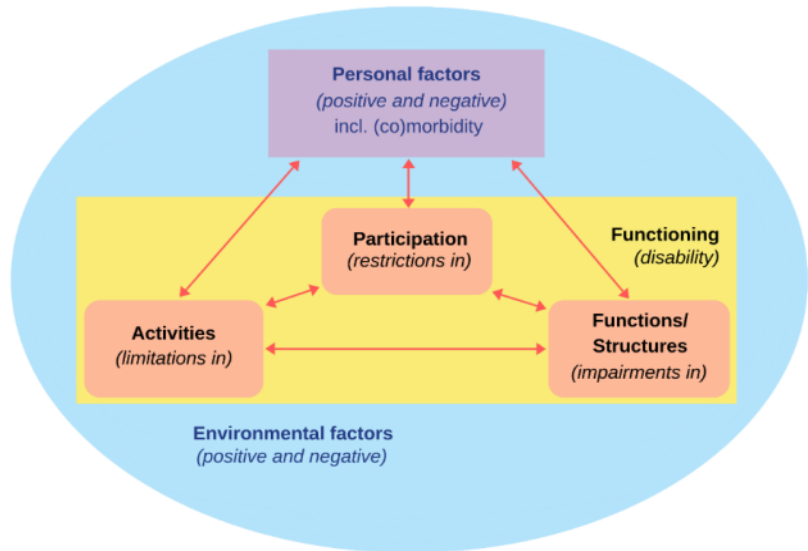

Figure 3. Third model suggestion - Participation as a central element ${ }^{5}$

Another suggestion consisted of a triangular base pyramid with a) Personal Factors, b) Environmental Factors, c) Activities, and d) Body Functions and Structures positioned in the vertices, with Participation in the centre of the pyramid, reserving the central position of Participation. All the components were connected by double-headed arrows [Figure 4]. ${ }^{6}$

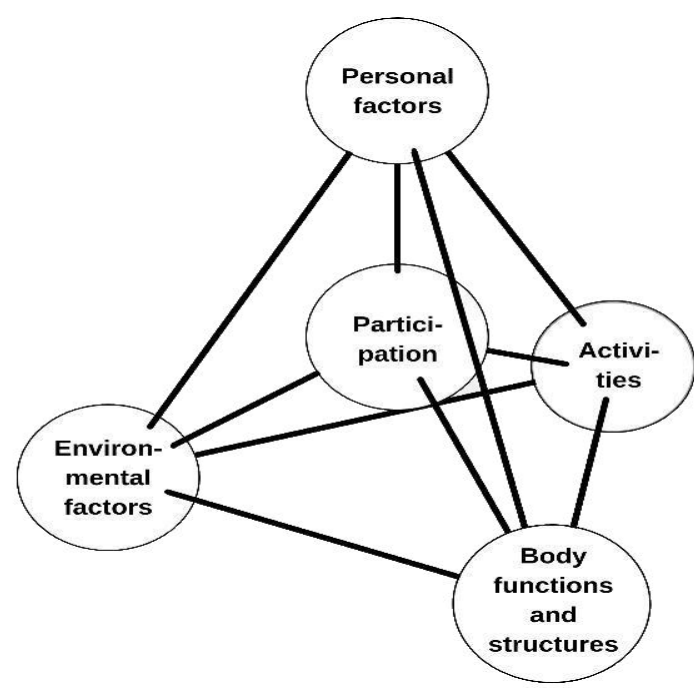

Figure 4. Fourth model suggestion - pyramid with Participation as central element ${ }^{6}$

In another letter to the editor, two new schemes were introduced. The first is a triangle with the following components in its vertices: a) Personal Factors (including: [co]morbidity and Functions/Structures), b) Environmental Factors, and c) Activities. This scheme would still 
have Lived Experience (Participation) as a central component in the middle of the triangle [Figure 5].

The second scheme, which the authors call the 'transactional approach', is composed of three partially overlapping circles representing a) Personal Factors (including: [co]morbidity and Functions/Structures), b) Environmental Factors, and c) Activities. In the central area, where all the circles overlap, is located Lived Experience (Participation), which is emphasized through its central position [Figure 6]. ${ }^{7}$

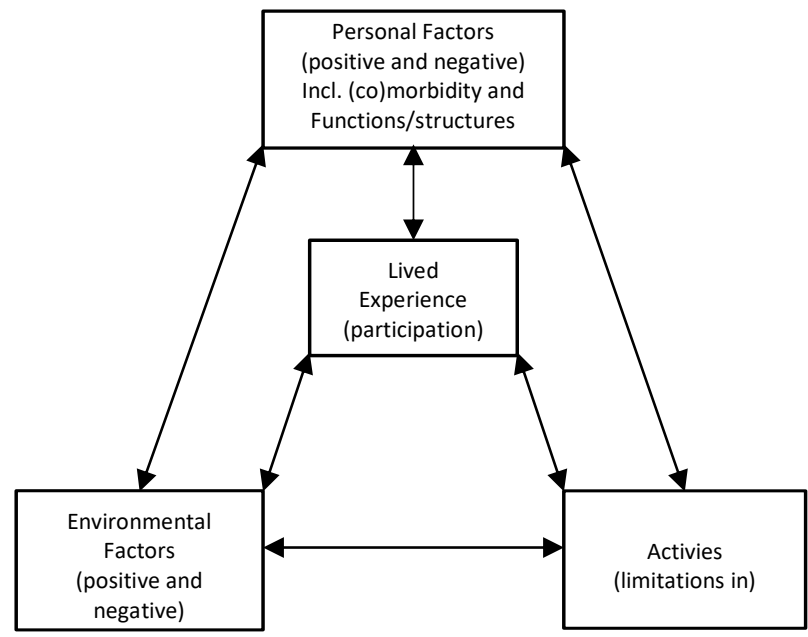

Figure 5. Fifth model suggestion - triangle with Participation (Lived Experience) as central element ${ }^{7}$

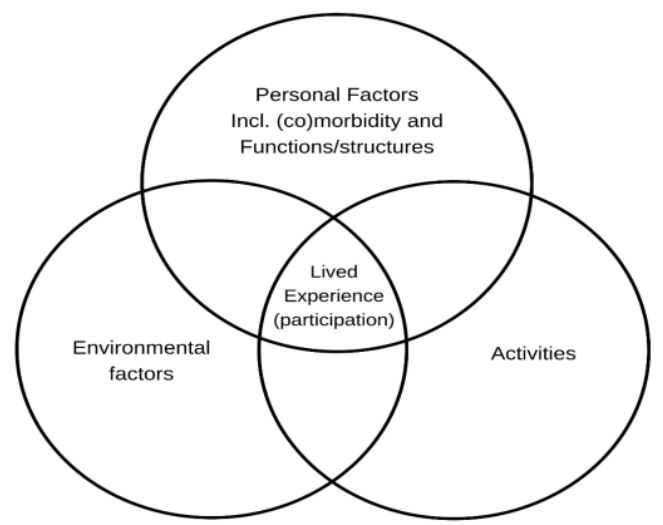

Figure 6. Sixth model suggestion - 'transactional approach' with Participation (Lived Experience) as central element ${ }^{7}$

The last publication used the following components: a) Environmental Factors, b) Personal Factors, c) Functioning, and d) Medical Factors in a linear integration of perspectives. In this scheme, Functioning is also based on Activities, Participation, and Functions/Structures [Figure 7]. ${ }^{8}$

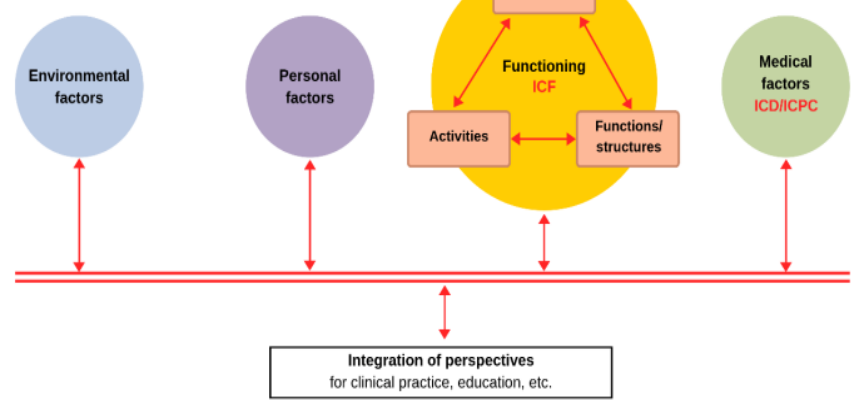

Figure 7. Seventh model suggestion - Functioning as a result of Participation, Activities and Functions/Structures interaction ${ }^{8}$

\section{ICF scheme suggestion}

Sometime after the debate was started and after learning, reflecting on and building constructive criticism about the arguments presented by the proposed schemes, we felt it was appropriate to continue the discussion convened ${ }^{5}$ and submit our suggestions for consideration.

The scheme we present for discussion retains all the components of the original ICF scheme, separately. Therefore, our scheme has the following components: a) Participation, b) Health Condition, c) Activities, d) Body Functions and Structures, e) Environmental Factors, and f) Personal Factors. In our scheme, all the components are placed equidistantly in a 'ball shell' structure, linked by double-headed arrows. Apparently, the Health Condition component does not play the role it was supposed to. ${ }^{9}$

However, as we understand that it is still an essential element in people's functioning profile, we decided to maintain it in the scheme. Another feature that we have kept in our proposal is the ICF system perspective believing that functioning is settled down in the balance of this system. In our scheme, all components are directly connected to each other with double-headed arrows, as well. The proposed scheme can be seen in the supplementary Video 1.

As in another scheme already presented in this discussion, ${ }^{6}$ we also adopted the three-dimensional (3D) perspective. We believe that the complexity involved in the functioning concept requires a perspective that is beyond two-dimensional (2D) schemes. Such a decision has a didactic motivation, considering how visualized theory can be seen as a way of improving the understanding of abstract concepts ${ }^{10}$ through the influence of visual perception in the mental processes of comprehension. ${ }^{11}$

The biopsychosocial perspective of functioning, proposed by the ICF model, is difficult to visualize, given its abstract nature. The ICF scheme, as the representative image of that theoretical model, is a symbol, a visual representation of that non-visible entity. Thus, the 3D representation in this paper would have the potential to help understand the meaning of the idea that it intends to depict: the dynamic interactions between the components of the ICF model.

The aspects presented thus far would be those coincident with the models already cited. It should be stressed that the innovative perspective of our scheme is fourfold. First, there is no central component. Our belief is that the centrality of some element can place too much emphasis on one aspect, and this may not apply to all situations. Therefore, we propose that all components should be equally considered. Second, our scheme is not static. It can rotate on any of its three axes.

This dynamic rotational characteristic allows an essential component of the subject's functioning to be positioned at the front and middle of the scheme, thus highlighting its importance regardless of the component. Third, the spheres of the model components have a modifiable scale and can be enlarged or reduced, depending on the magnitude of the component in the assessed functioning profile.

Finally, a gradation of colours is also used, where yellow is the most important and black is the least important. These last two features will provide a perspective of the component's significance in the person's functioning profile. We provide two supplementary Video 2 and Video 3 as examples of the functionalities discussed above.

\section{Concluding remarks}

This paper continues the discussion process of the ICF scheme revision, already started by other papers. The scheme properties that were highlighted in this paper make it possible to better understand the interactions between functioning components. At the same time, the magnitude or importance of each component can be more clearly shown. As a main result, health professionals could select clinical intervention targets more appropriately and carry out a patient- 
centered health care, given the unique functioning profile offered by the scheme.

It should be stressed that the scheme described here does not intend to exhaust the discussions about the theme, but to continue the debate already started, seeking further the process of ICF improvement. We are aware that the discussion on updating ICF scheme has to occur intensively and extensively, with the participation of people with disabilities, researchers, health professionals, health managers, and interested parties in all possible settings, not only in clinical, research, and teaching settings.

The more it is debated, the more improved a successor scheme will become, which will in turn further our understanding of functioning. In addition, it should be noted that this paper has a theoretical role and does not intend to present clinical applications of the proposed new model. It is our intention to present an alternative model of functioning so that the debate on potentialities and clinical applications is discussed later by the scientific community. In this way, we hope to have contributed to the discussion on ICF scheme improvement.

\section{REFERENCES}

1. Kostanjsek N. Use of The International Classification of Functioning, Disability and Health (ICF) as a conceptual framework and common language for disability statistics and health information systems. BMC Public Health. 2011;11 Suppl 4(Suppl 4):S3. Doi: http://dx.doi.org/10.1186/1471-2458-11-S4-S3

2. World Health Organization. International Classification of Functioning, Disability and Health (ICF). Geneva: WHO; 2001.

3. World Health Organization. Towards a Common Language for Functioning, Disability and Health ICF. Geneva: WHO; 2002.

4. Cerniauskaite M, Quintas R, Boldt C, Raggi A, Cieza A, Bickenbach $\mathrm{JE}$, et al. Systematic literature review on ICF from 2001 to 2009: its use, implementation and operationalisation. Disabil Rehabil. 2011;33(4):281-309.

Doi: http://dx.doi.org/10.3109/09638288.2010.529235

5. Heerkens YF, de Weerd M, Huber M, de Brouwer CPM, van der Veen S, Perenboom RJM, et al. Reconsideration of the scheme of the international classification of functioning, disability and health: incentives from the Netherlands for a global debate. Disabil Rehabil. 2018;40(5):603-11. doi: http://dx.doi.org/10.1080/09638288.2016.1277404
6. Borg J. The Participation Pyramid: a response to "Reconsideration ICF scheme" by Heerkens et al. 2017. Disabil Rehabil. 2018;40(1):123-124. http://dx.doi.org/10.1080/09638288.2017.1393700

7. Van de Velde D, De Vriendt P. Comment on: Reconsideration of the scheme of the International Classification of Functioning, Disability and Health: incentives from the Netherlands for a global debate. Heerkens et al, 2017. Disabil Rehabil. 2018;40(5):612-614. Doi: http://dx.doi.org/10.1080/09638288.2017.1300329

8. Tange $\mathrm{H}$. Comment on 'Reconsideration of the scheme of the international classification of functioning, disability and health' by Heerkens et al. (2017). Disabil Rehabil. 2018;40(5):615. Doi: http://dx.doi.org/10.1080/09638288.2017.1302005

9. Dutra FC, Mancini MC, Neves JA, Kirkwood RN, Sampaio RF. Empirical analysis of the International Classification of Functioning, Disability and Health (ICF) using structural equation modeling. Braz J Phys Ther. 2016;20(5):384-394. Doi: http://dx.doi.org/10.1590/bjpt-rbf.2014.0168

10. Swedberg R. Can You Visualize Theory? On the Use of Visual Thinking in Theory Pictures, Theorizing Diagrams, and Visual Sketches. Sociological Theory. 2016; 34(3):250-75. Doi: https://doi.org/10.1177/0735275116664380

11. Cantor RM. Conceptual embodiment in visual semiotics. Semiotica. 2016;210:215-23. Doi: https://doi.org/10.1515/sem2016-0052 